\title{
THREE-DIMENSIONAL RECORDING AND PHOTOREALISTIC MODEL RECONSTRUCTION FOR VIRTUAL MUSEUM APPLICATION - AN EXPERIENCE IN MALAYSIA
}

\author{
O. C. Wei, Z. Majid, H. Setan, M. F. M. Ariff, K. M. Idris, N. Darwin, A. R. Yusoff, K. Zainuddin
}

Geospatial Imaging and Information Research Group, Faculty of Built Environment and Surveying, Universiti Teknologi Malaysia (zulkeplimajid, mfaridma, khairulnizami,nurhadija2)@utm.my, khairul760@ perlis.uitm.edu.my, (ahmadrazali89, ongcheewei86)@gmail.com

\author{
Commission II
}

KEY WORDS: Three-dimensional, Photorealistic, Virtual Museum, Terrestrial Laser Scanning, Close-Range Laser Scanning

\begin{abstract}
:
In recent years, museums are utilizing the ability of virtual reality (VR) technologies to visualize their collections in three-dimensional (3D) environment. The demands for 3D digitization of cultural heritage have increase greatly to facilitate the development of virtual museum. Among the available techniques, the use of laser scanning for digital recording and 3D reproduction of the heritage sites and archaeological artefacts are technically more reliable due to its rapid and high resolution data capture. However, the suitable 3D laser scanners used greatly depend on the level of details and size of an object. This research used medium and close-range type of laser scanners to digitally record the heritage objects. The aim of this research was to develop methodology framework for digital recording and 3D reproduction of archaeological artefact and heritage sites in Malaysia by using terrestrial laser scanning technology. Besides, this research focused on the reconstruction of photorealistic 3D models based on the colour information yield by close-range photogrammetry. The colour descriptions were obtained either by built-in camera or externally integrated camera on the laser scanner. For better colour descriptions, external images were captured by independent Nikon D300s digital camera. The geometric model accuracy of A'Famosa and terracotta Buddha statuette was in $5 \mathrm{~mm}$ and $0.41 \mathrm{~mm}$ respectively. 3D flythrough animation was rendered by using the coloured point clouds model. The development of 3D Virtual Walkthrough Museum (3DVWM) utilized the 3D PDF document and SCENE WebShare platform to offer realistic visualization experience to the visitors where the reality-based models could be manipulate in 3D geometric aspects and use of metric analysis. Thus, 3DVWM can facilitate the virtual museum application in Malaysia and enable wider visitors to virtually appreciate the cultural heritage in Malaysia. Thus, this indirectly stimulates the tourism industry in our country.
\end{abstract}

\section{INTRODUCTION}

According to International Council Museums (ICOM, 2007), museum is a non-profit making, permanent institution where collections of the cultural heritage is protected and exhibited to the public. The collections of artefacts in the museums can provide a valuable sense of connection between the past and the present and serve as a springboard for the future (Ambrose and Paine, 2006).

In the past, museums provide only a simple hyper-link text with graphics which presented the basic information about the museum and the exhibit collections. However, museum begin to realize the potential of new advanced technologies in creating $3 \mathrm{D}$ digital contents and VR technologies for interactively visualize individual reality-based models of artefacts in a virtual environment (Rizvic et al., 2011).

Recently, great demand on developing the virtual museum has facilitates the need for cultural heritage digitalization. Digitalization of cultural heritage is the process of digitizing the archaeological artefacts and historical sites using modern scanning devices and virtual technologies to achieve 3D digital archiving, for the purpose of protection, reparation, restoration, and archaeological research ( $\mathrm{Lu}$ and Pan, 2010). Hence, 3D digital models are always a critical component to permanently record both the geometry and texture of heritage objects with high precision (Remondino and Rizzi, 2010).

*corresponding author
Digital preservation of cultural heritage uses various 3D digitizing methods to capture archaeological information that involves multiple processes (Pavlidis et al., 2006). With rapid development in 3D digital technologies, conventional documentation of cultural heritage is now evolved from the simple hand-draw sketches to sophisticated fast and precise digital recording and 3D modelling of cultural heritage (Tsirliganis et al., 2004). Representative examples include the Great Buddha Research (Ikeuchi et al., 2007), Stanford University's Michelangelo Research (Levoy et al., 2000), and 3D Documentation of A'Famosa Fortress (Ong et al., 2010; 2011).

The available technologies and methodologies for digital recording of cultural heritage are really promising and the whole heritage community is trying to adapt these approaches for fastest, detailed and easy 3D documentation (Campana and Remondino, 2007; Remondino and Rizzi, 2010). Nowadays, the most common techniques used for $3 \mathrm{D}$ recording and modelling are based on photogrammetry (Andres et al., 2012; Remondino and El-Hakim, 2006) and laser scanning (Alshawabkeh, 2005; Tucci and Bonora, 2007; Ong et al., 2010; 2011).

Through the above mentioned techniques, it is possible to create photorealistic 3D models of heritage objects ranging from very small object to whole building structures. Both approaches have advantages and disadvantages which the choice is done according to the budget, research size, required detail and accuracy (Remondino and Rizzi, 2010). There are also hybrid techniques that capable of giving very realistic 3D virtual model for large environments or complex heritage sites (Lamber et al., 2007). 
The availability and use of 3D virtual model of heritages opens a wide range of further applications and permits new conservation policies as well as new exploration view of archaeological heritage offered by virtual museum. Thus, virtual heritages should be frequently using in cultural heritage world so that museum visitors and researchers can access to computer reconstructions of historical sites or artefacts that would normally be inaccessible, due to location and fragile condition (Jaafar et al., 2010).

In recent years, the development of virtual museum is increasingly attracting the attention of museum curators and researchers. A virtual museum recovers many limitation issues of a traditional museum, through utilizing some advanced 3D VR technologies. A virtual museum is a platform dealing with the digital heritage and information resources virtually through the use of digitalization. It utilizes information technology such as computer graphic technology, virtual reality technology and multimedia database technology (Lu and Pan, 2010).

This research aimed to develop a complete methodology framework for 3D recording and digital reproduction of archaeological artefacts and historical sites in Malaysia by using terrestrial laser scanning (TLS) technique. Additionally, this approach also demonstrates the hybrid technique of TLS and close-range photogrammetry (CRP) to produce high resolution photorealistic 3D models for virtual museum application. To obtain the high quality of photorealistic 3D models, the 3D photorealistic reconstruction procedure was evaluated by using the 3D data obtained by TLS. This research also illustrated the creation of VR systems based on the reality-based models, 3D PDF documents and 3D animation, which allows the user to interact in an interactive way with the rich collection of archaeological artefacts and historical sites.

\section{STATE OF THE ART OF 3D VIRTUAL MUSEUM}

The early idea of a virtual museum was a replica of the physical museum in its architecture design and it generally contained 2D and 3D items from the museum's collections. The term Virtual Museum was first coined by Tsichritzis and Gibbs (1991) and it has been used in their article titled Virtual Museums and Virtual Realities where they explained the development of a virtual museum and the technologies needed to construct a virtual landscape. The virtual museum later evolved to an online museum that contained different types of media (multimedia) to present information, such as images, text, video etc. However, virtual museum is today much more complexity than just different types of media-presented information on a website.

Therefore, it is essential that proper planning and investigation be carried out before commencing the development of a virtual museum and the digitized phase. According to Rahim et al. (2011), the research on usability of virtual museum in Malaysia still lacks of seriousness. There are still problems in interface design of virtual museum as the presentation of the exhibition by the museum is still not steady enough and lack of acceptance from the users. There are few existing virtual museum in Malaysia which are Museum Malacca, Museum Sarawak, Museum Negara and Penang State Museum. But all of them are still having limitation to act as an alternative to convey information and provide real experience as in the real locations to interact through virtual environments.

A virtual museum is defined as a set of digitally recorded images, sound files, text documents, and other information of historical, scientific, or cultural interest that are published through electronic media. A virtual museum does not house actual objects and therefore lacks the permanence and unique qualities of a museum in the institutional definition of the term.

Nowadays, virtual museum is no longer only a website with information presented through multimedia or a website connected with a database. Today, creating a database on a website does not make it a virtual museum. As described by Kaczmarek (2008), a virtual museum is not merely a database of digitised images linked to powerful information retrieval software. The major essential part of the virtual museum is accessibility.

According to Mitsumine et al. (1996) and Kulur and Yilmaztürk (2005), a virtual museum may have the following requirements and characteristics:

- The virtual museum must be easy to use.

- Allow visitors to view and manipulate the exhibits from various angles.

- Offers much different kind of entertainment activities besides preservation possibility.

- $\quad$ Provide more vivid and realistic experience

- Increase desire to visit the original museum building.

- Allow users to measure, records and analyze the historical objects, which are fragile and need special handling.

- Explanation of art objects should be given by sound and texts.

To sum up, a virtual museum is a source of information on the internet, or alternatively on various storage medium, but then in a form that is fixed and restrained in dynamic capabilities. The online museum provides information through multimedia interface that allow user to navigate and experience the virtual museum. Information is as essential to the virtual museum as objects are for a physical museum. The lack of object authenticity in the virtual museum is instead replaced with the authenticity of information. Through its position on the Internet the online museum is accessible through connection technologies widely diffused. This gives it an advantage that the physical museums cannot make.

3D digitization and modelling of exhibits was the first phase of the overall process to complete the development of virtual museum. It consists of multiple processes and exhibits variations in accordance with specific requirements. Consequently, the creation of the virtual museum environment was constructed by means of 3D modelling techniques and interactive design was applied till the environment accomplished the requirements.

3D digitization of archaeological finds is the first step of the overall process of developing a virtual museum. It consists of multiple process and exhibits variations in accordance with specific application requirements. Due to the complexity of the digitization needs and the requirements set, there are a number of methods and technologies used for exhibits' digitization and the creation of $2 \mathrm{D}$ and $3 \mathrm{D}$ objects.

There are several techniques can be used to obtain 3D artefact models of the virtual museum. The digitised 3D objects must have reliable metric characteristics and can be visualized. Therefore, a complete geometric recording of the objects must be performed. Most documented researchs on cultural heritage have used imagebased technique, range-based technique or combination of both techniques. However, there are no set rules for which technology and technique or software to use for a given application. It should be noted that choosing an appropriate digitization system to fulfil 
a particular demands and needs of a specific digital documentation research is very important.

Digital CRP measures objects directly from photographs or digital images captured with a camera at close range. The term $\mathrm{CRP}$ is used to describe the technique when the camera is positioned close to the measured object and the size of the object is less than $100 \mathrm{~m}$. Images are acquired from camera positions all around the object. CRP approaches would require devices that provide images such as film-based cameras, analogue video cameras or digital still-frame cameras/video cameras.

Laser scanning technology uses a device that analyzes real-world objects and environment by measuring $3 \mathrm{D}$ points through an array of coordinates with high density and accuracy in a short period of time. A laser scanner used the reflection and researchion of laser beam to calculate object distances by measuring the time of travel for wavelength pulses that reflect off objects and return to the sensor. As a result, millions of points in local coordinate system with intensity values are generated from scanned position. This information then can be manipulated using CAD software to generate a 3D model and the as-built drawings. Furthermore, additional information such as RGB values can be collected by internal or external digital cameras. Laser scanners have the potential to be widely used as a $3 \mathrm{D}$ and non-destructive recording tool in archaeological applications, mainly in cases where contact with the object surface should be avoided. Laser scanning technology can be divided into two categories which are airborne and terrestrial. Airborne laser scanning often referred to as Light Detection and Ranging (LiDAR), is a relatively new active remote sensing technology for the capturing of topographic data.

Generally, terrestrial laser scanner can be classified into three principles: time-of-flight, phase-shift measurement and triangulation (Fröhlich and Mettenleiter, 2004). Normally, timeof-flight and phase-shift measurement scanner are for large object while triangulation based scanner is suitable for measuring small object in close range. In order to get an accurate 3D point cloud data of the whole object surface there are two factors that need to be concerned such as distance accuracy and space resolution of the laser scanner.

Although terrestrial laser scanning can record all the details, it is usually not practical to implement as the only technique for every object and structure due to insufficient data on linear and edge surface features. Laser scanning technique cannot identify the colour of the measured surface even though can produce dense and huge point clouds fast and reliable.

CRP alone will have difficulty with irregular and sculpted surfaces. Photogrammetric procedures are still highly dependent on lighting conditions, texture features and human interaction. Techniques using small number of widely separated views do not offer a high level of automation and have problems with occluded and unmarked surfaces. Therefore, in most cases, a proper combination of both TLS and CRP techniques are able to produce better 3D textured model when the characteristics of the research area are complex and with large dimensions. In recent years, many researchers have combined both photogrammetry and TLS in different ways.

\section{RESEARCH METHODOLOGY}

Figure 1 shows the overall flowchart of the methodology carried out in the research.

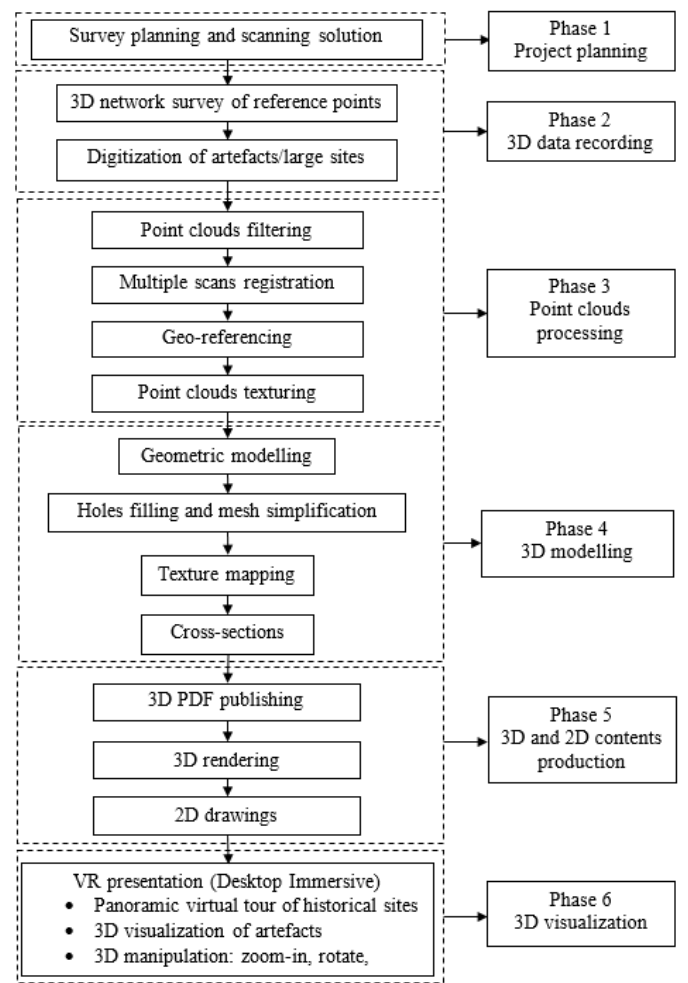

Figure 1. Overall research methodology

\subsection{Phase 1: Research Planning}

This phase played an important role in producing a good archive of cultural heritage with respect to measuring preciseness and photographic quality. The main works of this phase involved choosing the suitable recording technique, determining the type of scanner used, understanding the scan environment, determining the optimal scanning position and targets location, determining the point density at different scanning range, and determining final deliverables.

\subsection{Phase 2: 3D Data Recording}

The major goal for this phase was to precisely record the 3D spatial information of the historical buildings and archaeological artefacts. The data recording was divided into two categories: archaeological artefacts recording and historical buildings recording. The historical buildings recording included the recording of A'Famosa fortress and Bujang Valley Archaeological Museum. In this recording process, two different types of terrestrial laser scanners, medium-range and close-range laser scanner was used to record the historical building and archaeological artefacts facades respectively.

To document the whole A'Famosa fortress, the recording process involved interior and exterior scanning (as in Figure 2). The documentation procedure was divided into two parts: laser scanning and image capturing. This research demonstrated the combination of TLS and digital photogrammetry to obtain the complete digital archiving of this historical building. In laser scanning, the geometry data was scanned by FARO Photon 120 whereas the texture information was captured by an integrated high resolution Nikon DSLR D300s camera. 


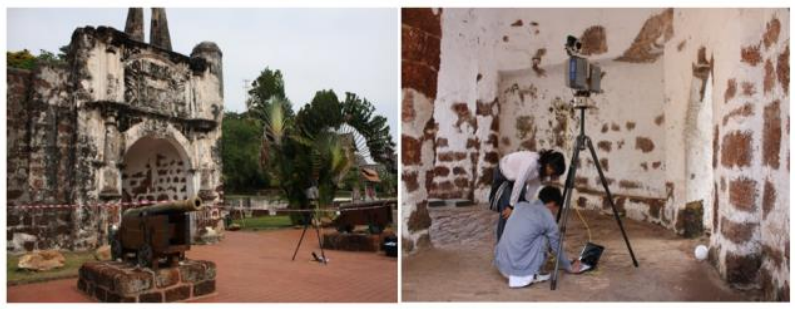

Figure 2. Scanning of A'Famosa fortress

The similar laser scanner system, FARO Photon 120 was used to execute the recording process of Bujang Valley Archaeological Museum. Generally, the scanning procedures and configurations were same as conducted for A'Famosa fortress. The documentation process involved interior scanning and exterior scanning (as in Figure 3).

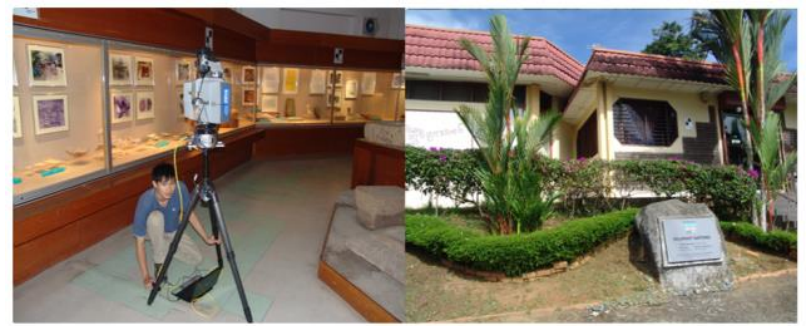

Figure 3. Scanning of Bujang Valley archaeological museum

In this research, the Konica Minolta Vivid 910 scanner was used to produce 3D point clouds data of an artefact (as shown in Figure $4)$.

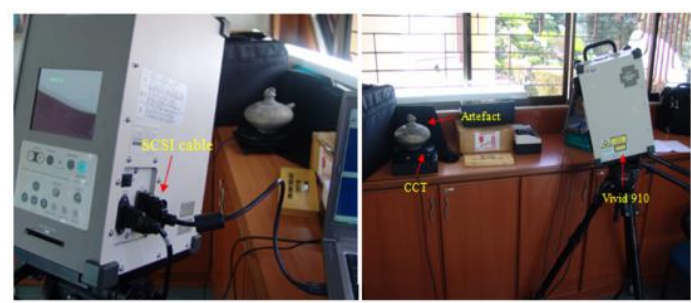

Figure 4. Scanning of artefact using VIVID 910 scanner

\subsection{Phase 3: Point Clouds Processing}

Point clouds processing was another important stage of this research, where the acquired data was converted to digital archiving. This mainly includes data filtering, data registration and point clouds colourizing for different types of scanned data.

\subsection{Phase 4:3D Modelling}

In this phase, the 3D meshed model was constructed from the 3D point clouds by connecting all the neighbouring points to polygons using Geomagic Studio 2012. Geomagic Studio (GS) was the product from Geomagic Company, United State of America.GS was developed for automated reverse engineering uses. In this research, the A'Famosa point clouds model was chosen to elaborate the 3D modelling process. There were three phases involved to produce the photorealistic 3D model from point clouds such as Point Clouds Phase, Polygon Phase and Texture Mapping Phase.

\subsection{Phase 5: 2D and 3D Contents Production}

In this phase, 2D drawings such as cross-section (as shown in Figure 5), elevation and floor plans were extracted from point clouds data. For this research, the AutoCAD 2011 was used to process the point clouds directly with a special interface that enable to load huge point clouds into this program by using the standard CAD tools, which was a plug-in called Point Sense Cloud developed by Kubit. This plug-in software offered additional modelling tools to FARO SCENE which it could directly transfer the $2 \mathrm{D}$ or $3 \mathrm{D}$ coordinate of scan data to AutoCAD. Furthermore, it enables AutoCAD to handle millions of point clouds.

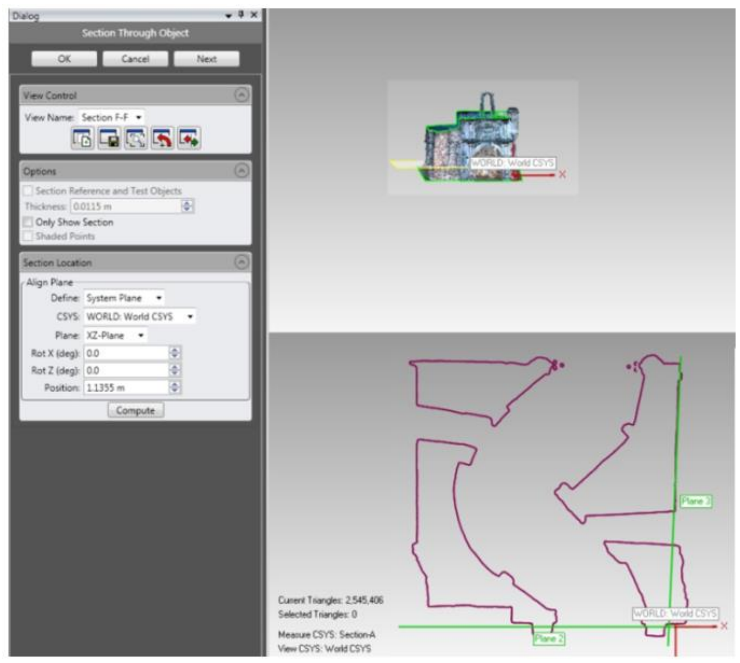

Figure 5. Creating a section plane through System Plane Method

A Bentley Pointools V8i software was used to render the Flythrough animation of the historical buildings in Malaysia from coloured point clouds. 3D Fly-through animation was one of the important outputs for digitalization of cultural heritage as this 3D presentation could offer audience or publics a great realism sensation of visiting the sites without physically present to the original sites. Before started the rendering process, the resulting coloured point clouds models had to be exported in *.pod file format which this steps was done directly in FARO SCENE 5.0.

In order to manipulate and share digital cultural contents, the Universal 3D (.U3D) file format was selected. According to Majorov (2005), this U3D file format was supported by Portable Document Format (PDF) and could be visualized using Adobe Reader on several platforms which provide a high quality exploring experience. In this section, the 3D PDF documents were created using Adobe Acrobat Pro Extended.

Once the 3D models of the cultural heritage were generated, these models were saved in *.U3D format and then inserted into the Adobe Acrobat Pro Extended for the creation of interactive 3D PDF document. 3D PDF allows annotations like hypertext links and comments could be added to $3 \mathrm{D}$ views by associating them to the geometry in the form of information layers rendered over 3D models (Manferdini and Garagnani, 2011).

Within the 3D PDF files, it was possible to use measurement tools that help to extract 2D dimensions of the 3D content. Furthermore, the 3D models were explored from different point of views within the PDF document. Additionally, 3D PDF document could be inserted as hyperlinks into on-line HTML pages so that connected Internet browsers could automatically show their contents in window. 


\subsection{Phase 6: 3D Visualization}

Finally, the interactive 3D PDF documents and Fly-through animations were visualized together using FARO SCENE WebShare. For this research, FARO SCENE WebShare was used to generate the panoramic scan images on the Internet browser, thus enabling museum to share scan information with other parties, institutions, and researchers without the need of additional software. This application allows users to easily rotate, zoom and make simple measurement on the scans images. In this research, the web-share data was created and visualized in locally access only. Subsequently, the 3D virtual tour of the heritage sites was visualized in SCENE Webshare (Figure 6).Webshare data needed to be generated from scan research in SCENE.

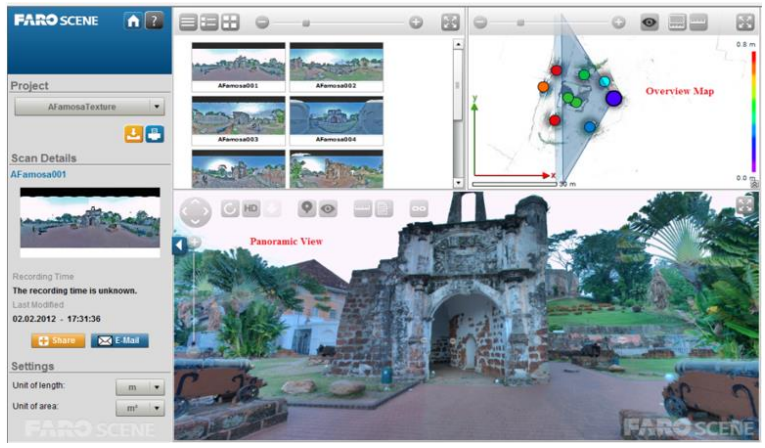

Figure 6. The A'Famosa fortress in SCENE WebShare View

\section{RESULTS AND ANALYSIS}

\subsection{Result and Analysis of 3D Geometric and Photorealistic Model}

In this section, the A'Famosa point clouds model was chosen to further the $3 \mathrm{D}$ modelling process in order to reproduce the $3 \mathrm{D}$ geometric and photorealistic model. The geometric model and photorealistic model of A'Famosa fortress was produced by using the GS 2012 software from the point clouds data. Geometric model was produced by interpolating the point clouds into triangular mesh. Figure 7 shows the 3D geometric model and some close-up views on the VOC logo and carving on the gate arch.

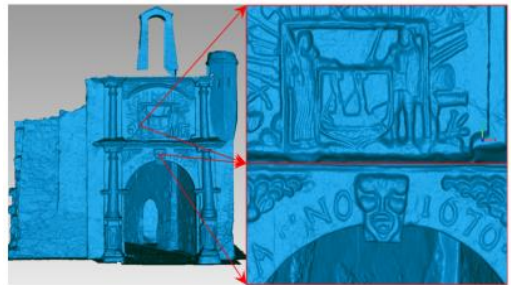

Figure 7. Geometric model of A'Famosa

It was important to evaluate the geometric model because this model was the main resource used to generate $3 \mathrm{D}$ photorealistic model. Hence, the geometric accuracy assessment was conducted by comparing the measurement of real fortress to the measurement of 3D model. Several measurements were made on the real fortress using measuring tape and these measurements were used as benchmark to compare with the measurement obtained in GQ 2012 (as in Figure 8).

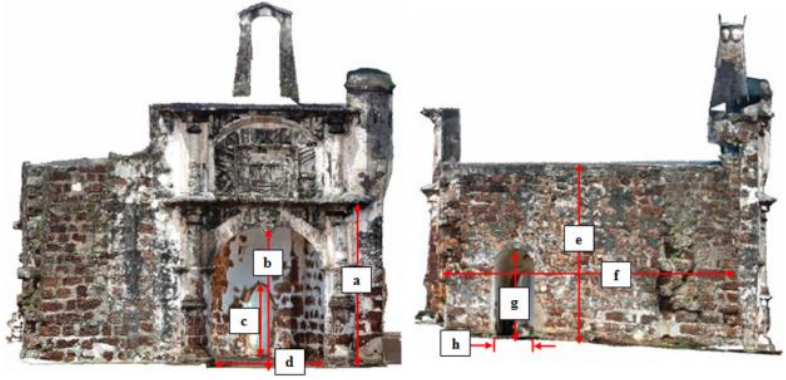

Figure 8. Measurements taken from A'Famosa façade

\begin{tabular}{|c|c|c|c|}
\hline Name & $\begin{array}{c}\text { Measurement } \\
\text { from real } \\
\text { fortress }(\mathrm{m})\end{array}$ & $\begin{array}{c}\text { Measurement } \\
\text { from 3D model } \\
(\mathrm{m})\end{array}$ & $\begin{array}{c}\text { Deviation } \\
(\mathrm{m})\end{array}$ \\
\hline $\mathrm{a}$ & 4.695 & 4.697 & 0.002 \\
\hline $\mathrm{b}$ & 3.863 & 3.866 & 0.003 \\
\hline $\mathrm{c}$ & 2.144 & 2.140 & 0.004 \\
\hline $\mathrm{d}$ & 3.314 & 3.320 & 0.006 \\
\hline $\mathrm{e}$ & 5.450 & 5.442 & 0.008 \\
\hline $\mathrm{f}$ & 9.350 & 9.355 & 0.005 \\
\hline $\mathrm{g}$ & 2.711 & 2.708 & 0.003 \\
\hline $\mathrm{h}$ & 1.301 & 1.295 & 0.006 \\
\hline \multicolumn{3}{|c|}{ Root mean square (RMS) error } & 0.005 \\
\hline
\end{tabular}

Table 1. Measurement differences between real fortress and 3D model

The difference between measurement from real fortress and measurement from 3D model were presented in Table 1. The measurement unit used for this comparison was in metres (m). From Table 1, the difference between both methods was $2 \mathrm{~mm}$ (minimum) to $8 \mathrm{~mm}$ (maximum). However, the RMS error for the measurements was $5 \mathrm{~mm}$. As stated by Georgopoulos and Ioannidis (2004), the accuracy required for detailed recording of heritage monument was $\pm 2 \mathrm{~mm}$ to $\pm 5 \mathrm{~mm}$. Thus, the assessment results showed that TLS technique was efficient to reproduce high quality and accurate digital model for cultural heritage.

Subsequently, the altered geometric model was then used in photorealistic reconstruction phase. Texture mapping the geometric model was a tedious work especially when the object has almost the same texture in all area. In this research, there were two methods employed to produce a photorealistic model (intrinsic colour and external image projection) as illustrated in Figure 9 and Figure 10, respectively.

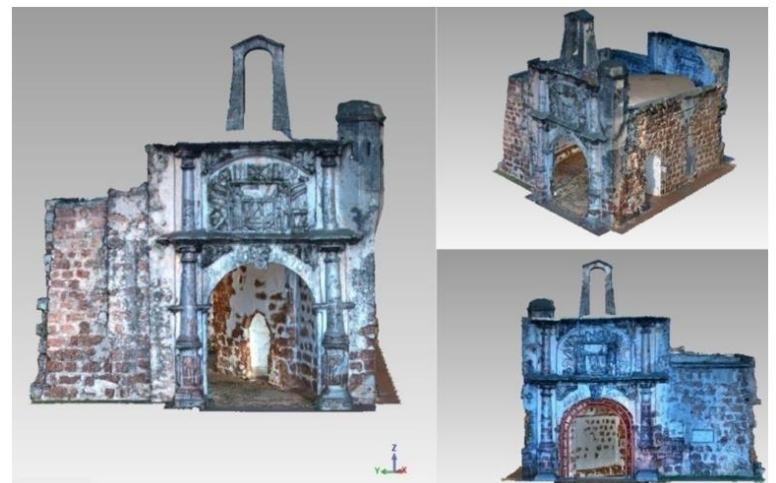

Figure 9. Multiple view of 3D photorealistic model of A'Famosa (intrinsic colour) 


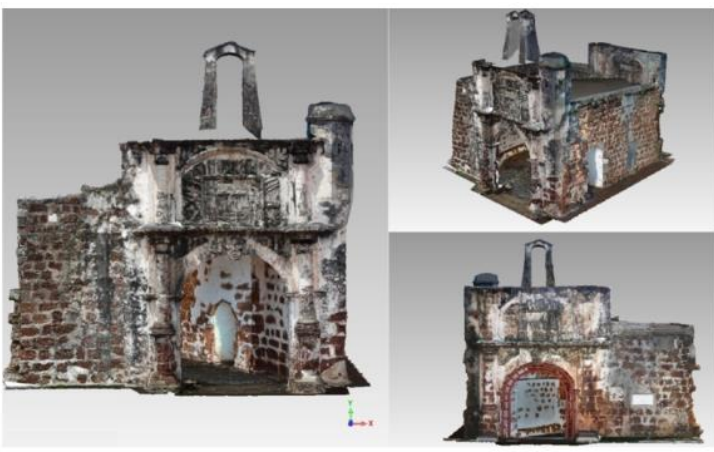

Figure 10. Multiple view of 3D photorealistic model of A'Famosa (external images)

The photorealistic model of A'Famosa contains about 10,332,585 triangles. The generated photorealistic model was evaluated based on visual analysis. The comparison between intrinsic colour model and photographic superposition model in term of texture description was done based on the high resolution images. Table 2 showed the visual analysis by comparing the texture descriptions.

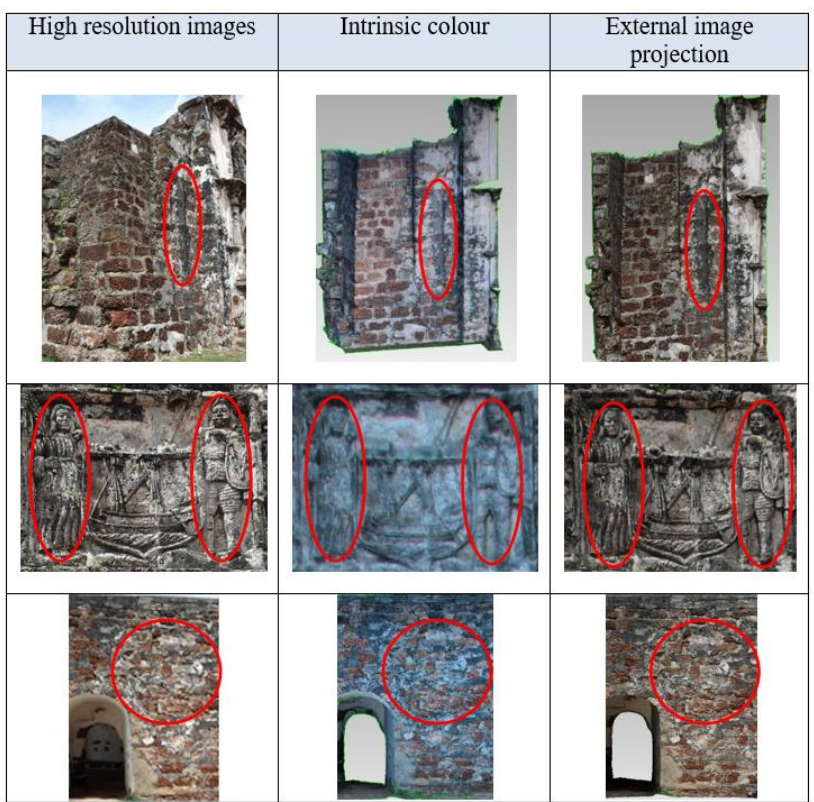

Table 2. Visual analysis - comparing texture description

In the sense of texture description, both of the techniques give a satisfaction results. Most of the fine features on the façade were successfully reconstructed on the digital model as presented in Table 2 (highlighted in red). However, the photorealistic model obtained from intrinsic colour was slightly poor in colour value. This was mainly due to the inadequate representation of the colour value which determined by the geometric resolution during scanning process. This was worst if the scanning was performed at outdoors where the camera parameters and lighting conditions could diff greatly.

Hence, in order to obtain better colour description the external high resolution images from independent digital camera was researched onto the mesh model. In this way, the created photorealistic model presented the closest possible texture descriptions to the original fortress. In conclusion, the intrinsic colour information could be as an alternative to provide a more life-like appearance for visualizing and rendering the point clouds model. If high colour resolution was required the second method was employed to enhance the analytical applications.

\subsection{Analysis of the 3D Geometric Model of Artefact}

In this section, the terracotta Buddha statuette was chosen and analyzed its surface deviation and geometric accuracy. Initially, the quality of the geometric model was evaluated by comparing the geometric model generated from GS 2012 with the point clouds model generated from PET by using GQ 2012. Figure 11 shows the surface deviation result of the geometric model.

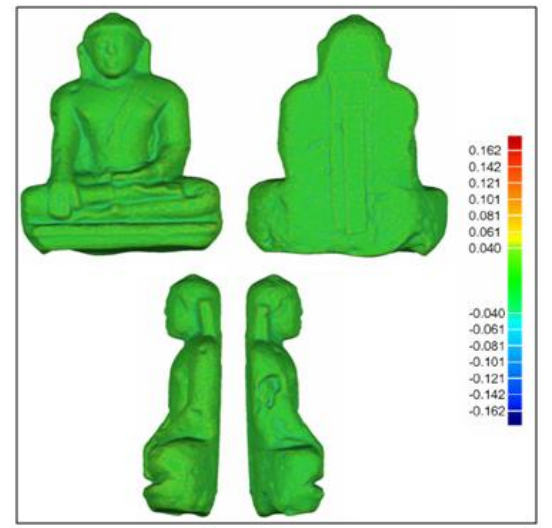

Figure 11. Surface deviation results (unit in $\mathrm{mm}$ )

As shown in Figure 11, the deviation value of the generated triangular mesh was very small compare to the original point clouds data. According to the $3 \mathrm{D}$ deviation test, the maximum upper deviation was $0.126 \mathrm{~mm}$ and the maximum lower deviation was $-0.153 \mathrm{~mm}$. Furthermore, the standard deviation was $0.011 \mathrm{~mm}$ whereas the average deviation was $\pm 0.009 \mathrm{~mm}$. Therefore, the generated terracotta Buddha model was claimed as an accurate and high quality 3D model.

Instead of analysing the geometric model based on the surface deviation, the geometric accuracy was used to evaluate the quality of the 3D model obtained from TLS technique. A comparison was made between the measurement obtained from the real artefact and the measurement obtained from the 3D model. In order to analysis the output data, several measurements were made on the real artefacts by using calliper and these measurements were used as benchmark to compare the measurement obtained by using GQ 2012 (as in Figure 12). The differences between measurement from real artefact and measurement from 3D model were presented in Table 3. Unit measurement used for this comparison was in millimetres $(\mathrm{mm})$.

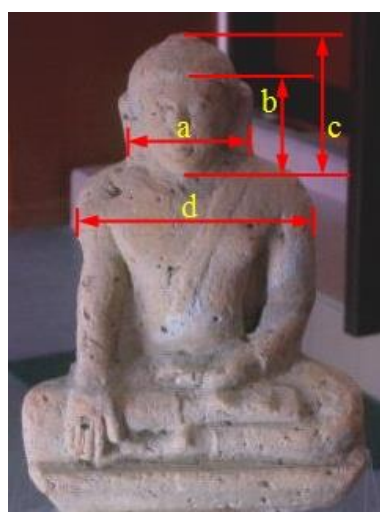

Figure 12. Measurement involved in the evaluation 


\begin{tabular}{|c|c|c|c|}
\hline Name & $\begin{array}{c}\text { Measurement } \\
\text { from real } \\
\text { artefact }(\mathrm{mm})\end{array}$ & $\begin{array}{c}\text { Measurement } \\
\text { from 3D model } \\
(\mathrm{mm})\end{array}$ & $\begin{array}{c}\text { Deviation } \\
(\mathrm{mm})\end{array}$ \\
\hline $\mathrm{a}$ & 69.55 & 69.11 & 0.44 \\
\hline $\mathrm{b}$ & 65.85 & 65.27 & 0.58 \\
\hline $\mathrm{c}$ & 86.00 & 85.79 & 0.21 \\
\hline $\mathrm{d}$ & 155.50 & 155.83 & 0.33 \\
\hline \multicolumn{3}{|c|}{ Root mean square (RMS) } & 0.41 \\
\hline
\end{tabular}

Table 3. Measurement differences between real artefact and 3D model

From Table 3, the difference between the measurement from real artefact and measurement from 3D model was $0.21 \mathrm{~mm}$ (minimum) to $0.58 \mathrm{~mm}$. These values were very small that they could be ignored. Then again, the RMS value for the measurements was about $0.41 \mathrm{~mm}$. By referring to Table 3.4 accuracy of measurement required for $100 \mathrm{~mm}$ feature size was \pm $5 \mathrm{~mm}$. Hence, it could be concluded that TLS technique was efficient to reproduce high quality and accurate archaeological artefact models.

Once the geometric model was verified, the cross-section was created by using Geomagic Qualify (GQ) 2012. In this research, the terracotta Buddha statuette was selected to perform the sectioning process. Several cross-sections were created as illustrated in Figure 13, Figure 14 and Figure 55. Some measurements were making on the cross-section for further analysis the dimension and volumetric of the statuette. The unit measurement used for the dimensioning was in millimetres $(\mathrm{mm})$.

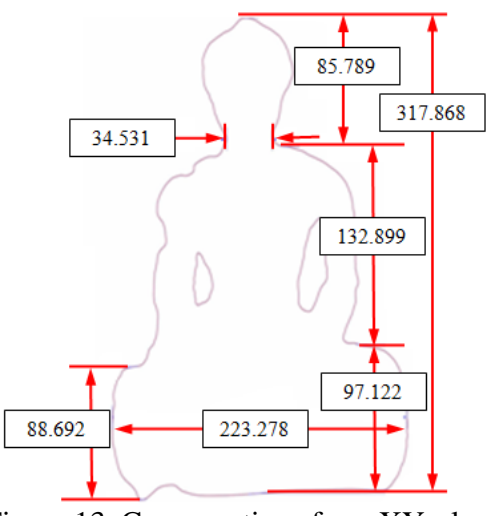

Figure 13. Cross-sections from XY-plane

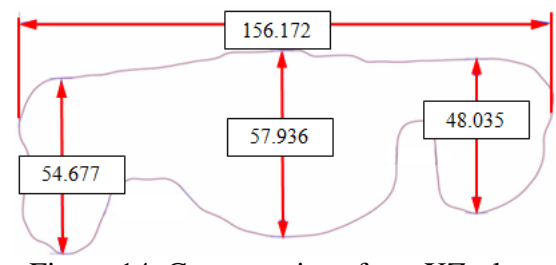

Figure 14. Cross-sections from XZ-plane

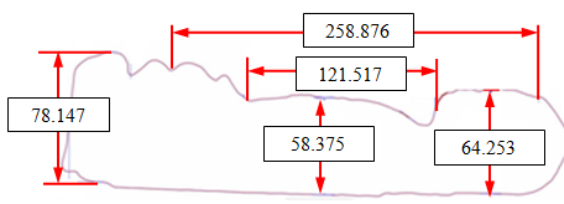

Figure 15. Cross-sections from YZ-plane

As illustrated in the Figure 13, the height of the terracotta Buddha statuette was $317.868 \mathrm{~mm}$. Besides, the length and width of statuette was $156.172 \mathrm{~mm}$ and $78.147 \mathrm{~mm}$. This model had the area of $145380.251 \mathrm{~mm}^{2}$ and with the volume of $2502404.575 \mathrm{~mm}^{3}$.
The evaluation of the photorealistic model of terracotta Buddha statuette was observed based on the geometric shape and texture descriptions. Figure 16 showed the comparison of the 3D model to the real statuette.

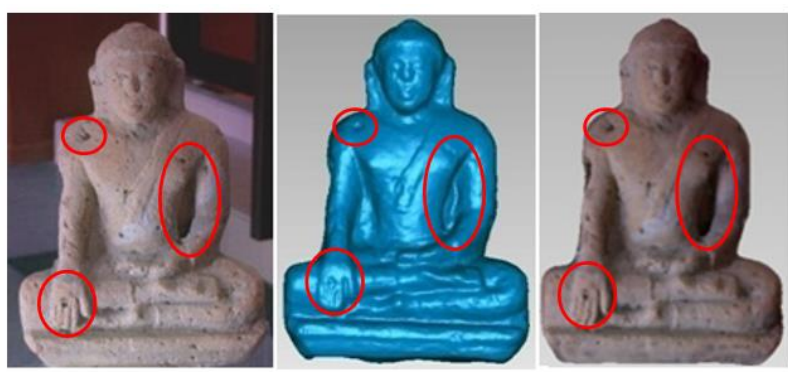

Figure 16. Comparison of the level of detail for terracotta Buddha statuette; real image (left), point clouds model (middle) and photorealistic 3D model (right)

From Figure 16, it could be seen clearly that most of the surface features (highlighted in red) on the terracotta Buddha statuette had been successfully reconstructed based on the dense point clouds data. Even though the colour values were obtained from the scanner, the photorealistic model was still enough to represent the geometric and texture resolution of the real statuette. Besides, the brightness of photorealistic model looks dim compare to the real one due to the lighting condition during image capturing. Therefore, an appropriate working environment and consistent lighting conditions were required in digitizing the archaeological artefacts. However, the overall performance of Vivid 910 scanner was capable and efficient to be employed for 3D digital reproduction of high quality photorealistic model.

\subsection{D PDF Publishing}

This section presented the photorealistic 3D model of the terracotta Buddha model that embedded in a 3D PDF document. The photorealistic 3D model and some descriptions of the statuette were combined into a single PDF file using Adobe Acrobat Pro Extended. Figure 17 showed the resulting PDF document that opened with Adobe Reader. As illustrated in Figure 17, the 3D content was visualized within a floating window that enables the model to been explored in 3D reality space. In the PDF document, it contains 3D measurement tools that allow users to make measurements on the 3D model which very useful for virtual analysis. The created PDF document was an ISO standard (ISO 32000-1:2008) and could be viewed by a number of platforms, hence it was an ideal format for offering more interactive 3D representation of cultural heritage in Malaysia to a larger audience.

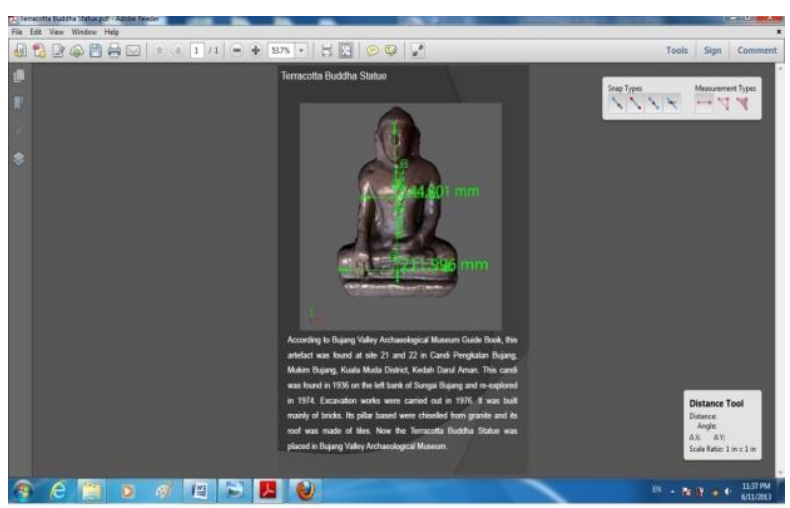

Figure 17. The resulting 3D PDF with embedded 3D terracotta Buddha Statue 


\subsection{D Visualization of Bujang Valley Archaeological Museum}

Figure 18 presented the Bujang Valley Archaeological Museum webshare data in SCENE WebShare view. Unfortunately, the visualization of the museum was only in grey scale due to the lens problem during image capturing. Figure 19 illustrated some measurements taken inside the museum gallery for analysis purpose.

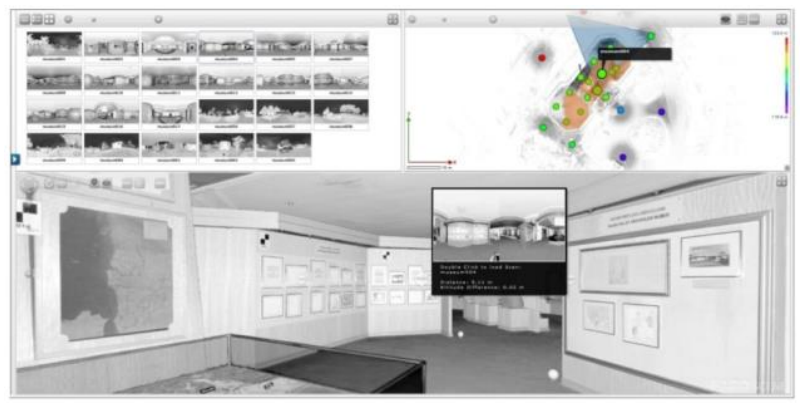

Figure 18. Bujang Valley Archaeological Museum in SCENE WebShare

As illustrated in Figure 19, each coloured circle in the Overview Map represents the scanner positions at different height. As it could be seen in the Figure 19, the measurement taken on the A4 checkerboard target was $0.297 \mathrm{~m}$ which proof that the measurement values was accurate for analysis. The height in the museum gallery was around $3.858 \mathrm{~m}$. The total area of the museum was approximately $429.956 \mathrm{~m}^{2}$.

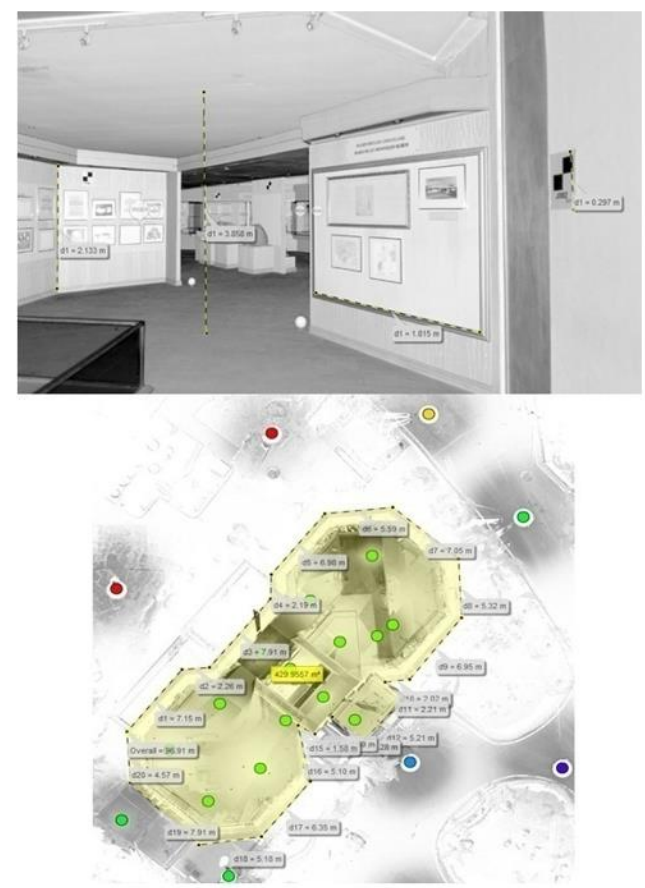

Figure 19: Measurement taken at the museum

In Figure 20, the documentation object was inserted in the panoramic view and attached to the desired points of interest. In this case, the 3D PDF document was placed on the terracotta Buddha Statuette. Hence, the digital model could be visualized and manipulated by audience in more interactive way within its 3D aspects.

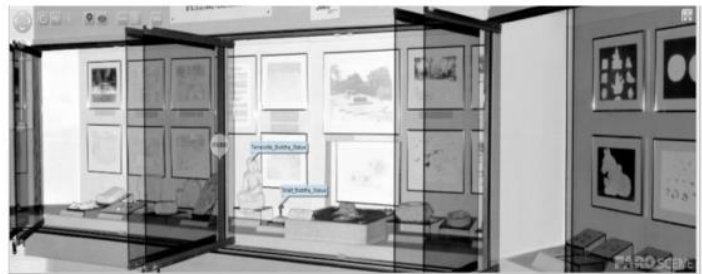

Figure 20. Documentation object of the Terracotta Buddha Statue

\section{Conclusion}

Based on the findings, several contributions have been successfully produced, such as:

- $\quad$ Provide adequate guidelines and methodology framework for archaeologist and conservator experts for 3D digitalization of heritage objects.

- Improve the existing documentation and conservation activities by providing complete and high accuracy $3 \mathrm{D}$ digital archiving.

- Sustain the current virtual museum development and visualize the cultural heritage in virtual reality environment.

- $\quad$ Enhance the museum exhibition experience through the 3D reality-based model which enables users to manipulate the artefact and heritage structure. Besides, the 3D flythrough animation gives visitors more realism sensation on visiting the heritage and museum sites.

\section{REFERENCES}

Ambrose, T. and Paine, C. (2006). Museum Basics. (2nd ed.). Madison Ave, N.Y.: Routledge.

Andrés, N, A, Pozuelo, B, F., Marimón, R, J. and Gisbert M, A (2012). Generation of virtual models of cultural heritage. Journal of Cultural Heritage. 13, $103-106$.

Al-shawabkeh, Y. (2005). Using Terrestrial Laser Scanning for the 3D Reconstruction of Petra/Jordan. International Archives of 'Photogrammetric Week 05', Heidelberg, Germany. 39-47.

Campana, S., and Remondino, F. (2007). Fast and Detailed Digital Documentation of Archaeological Excavations and Heritage Artifacts. Proceedings of 35th CAA Conference (Computer Applications and Quantitative Methods in Archaeology). Berlin, Germany, 36 - 42.

Fröhlich, C. and Mettenleiter, M. (2004). Terrestrial Laser Scanning - New Perspectives in 3D Surveying. International Archives of Photogrammetry, Remote Sensing and Spatial Information Sciences, XXXVI - 8/W2.

Ikeuchi, K., Oishi, T., Takamatsu, J., Sagawa, R., Nakazawa, A., Kurazume, R., Nishino, K., Kamakura, M. and Okamoto, Y. (2007): The Great Buddha Project: digitally archiving, restoring, and analyzing cultural heritage objects. Int. Journal of Computer Vision. 75(1), 189-208.

Jaafar, J., Mohamed, H. and Razali, H. (2010) Design and Development of Architectural Model Darul Ridzuan Museum. In: International Conference on Computer Science and Engineering (ICCSE 2010). 24-26 Feb. Penang, Malaysia. 
Kaczmarek, A.L. (2008). Exploring contexts of cultural objects in virtual museum. $1^{\text {st }}$ International Conference on Information Technology. 18-21 May, Gdansk, 1, 2.

Kulur, S. and Yilmaztürk, F. (2005). 3D-Reconstruction Of Small Historical Objects To Exhibit In Virtual Museum By Means Of Digital Photogrammetry. CIPA XX International Symposium, International Cooperation to Save The World's Cultural Heritage. 26 September- 01 October, Torino, Italy.

Levoy, M., Pulli, K., Curless, B., and Rusinkiewicz, S., Koller, D., Pereira, L., Ginzton, M., Anderson, S., Davis, J., Ginsberg, J., Shade, J. and Fulk, D. (2000) The Digital Michelangelo Project: 3D scanning of Large Statues, Computer Graphics and Proceedings: Annual Conference Series, SIGGRAPH 2000. 23 28 July. New Orleans, Louisiana, 131-144.

Lambers, K. and Remondino, F. (2007). Optical 3D measurement techniques in archaeology: recent developments and applications. Proceeding of 35th CAA Conference (Computer Applications and Quantitative Methods in Archaeology). Berlin, Germany, 27 - 34

Lu, D. and Pan, Y.H. (2010). Digital Preservation for Heritages. Technologies and Applications. London: Springer-Verlag.

Mitsumine, H., Noguchi, H. and Enami, K. (1996). Virtual Museum 3D fine art appreciation system. IEEE Transactions On Broadcasting. 42(3), 200-207.

Ong, C.W., Cheong, S.C., Majid, Z. and Setan, H. (2010). 3D Documentation and Preservation of Historical Monument using Terrestrial Laser Scanning. Geoinformation Science Journal, 10(1), 73 - 90.

Ong, C.W., Cheong, S.C., Majid, Z and Setan, H. (2011). Threedimensional Reocording and Visualization of A'Famosa fortress by using Terrestrial Laser Scanning. In: A-Qawasmi, J., Alshwahkeh, Y. and Remondino, F. (Eds.) Digital Media and its Application in Cultural Heritage (pp.119-136). Arman: The Center Csaar for The Study of Architecture (CSAAR) Press.

Pavlidis, G., Koutsoudis, A., Arnaoutoglou, F., Tsioukas, V. and Chamzas, C. (2007). Methods for 3D digitization of Cultural Heritage. Journal of Cultural Heritage. 8(1), 93-98.

Rizvic, S., Sadzak, A., Ramic-Brkic, B. and Hulusic, V. (2011). Virtual Museums and Their Public Perception In Bosnia and Herzegovina. ISPRS Workshop '3D-ARCH 2011'"3D Virtual Reconstruction and Visualization of Complex Architectures". 2 4 March. Trento, Italy.

Remondino, F. and Rizzi, A. (2010). Reality - based 3D documentation of naturaland cultural heritage sites: techniques, problems and examples. Appl Geomat. 2, 85-100.

Remondino, F. and El-Hakim, S. (2006). Image based 3D Modelling: A Review. The Photogrammetric Record, 21(115), $269-291$

Rahim, N., Tengku Wook, T.S.M. and Mat Zin, N.A. (2011). Developing Conceptual Model of Virtual Museum Environment Based on User Interaction Issue. In Badioze Zaman, $\mathrm{H}$., Robinson, P., Petrou, M., Olivier, P., Shih, T.K., Velastin, S. (Eds). Visual Informatics: Sustaining Research and Innovations (pp.253-260). Malaysia: Springer-Verlag Berlin Heidelberg.
Tsirliganis, N., Pavlidis, G., Koutsoudis, A., Papadopoulou, D., Tsompanopoulos, A., Stavroglou, K., Loukou, Z. and Chamzas, C. (2004). Archiving Cultural Objects in the 21st Century. Journal of Cultural Heritage. 5, 379-384

Tucci, G. and Bonora, V. (2007). Application of High Resolution Scanning System for Virtual Moulds and Replicas of Sculptural Work. Proceedings of the 21th CIPA. 1 - 6 October. Athens, Greece, 721-726.

Tsichritzis, D. and Gibbs, S. (1991). Virtual Museums and Virtual Realities. Proceedings of the International Conference on Hypermedia and Interactivity in Museums, Pittsburgh.

Revised May 2018 